\title{
Antibiofilm Activity of Synthetic Peptides Against Candida Albicans and C. Krusei: Action Mechanisms and Clinical Application to Overcome the Resistance Towards Antifungal Drugs Running Title: Antibiofilm Activity of Synthetic Peptides
}

\section{Leandro P. Bezerra}

Federal University of Ceará

Ayrles F.B. Silva

Federal University of Ceará

Jackson L. Amaral

Federal University of Ceará

Nilton A.S. Neto

Federal University of Ceará

Rafael G. G. Silva

Federal University of Ceará

Mônica O. Belém

Christus University Center

Claudia R. Andrade

Christus University Center

Jose T. A. Oliveira

Federal University of Ceará

Cleverson D.T. Freitas

Federal University of Ceará

Pedro F. N. Souza ( $\square$ pedrofilhobio@gmail.com )

Federal University of Ceará

\section{Research Article}

Keywords: Antibiofilm activity, Candidiasis, Synergism, Candida, Synthetic peptides, Antifungal drugs, Nystatin and Itraconazole, Action mechanisms, Clinical application

Posted Date: September 21st, 2021

DOl: https://doi.org/10.21203/rs.3.rs-909025/v1 
License: (c) (i) This work is licensed under a Creative Commons Attribution 4.0 International License. Read Full License 


\section{Abstract}

Yeasts belonging to the Candida genus are important human pathogens. Candida biofilm is the most common resistance mechanism, which could increase in 1000 times the resistance to antifungal drugs. This study aimed to evaluate the antibiofilm activity of synthetic peptides, as well as action mechanisms and synergistic effect with Nystatin (NYS) and Itraconazole (ITR) by Scanning Electron Microscopy (SEM) and Fluorescence Microscopy (FM). ITR $\left(1000 \mu \mathrm{g} . \mathrm{mL}^{-1}\right)$ inhibited $10 \%$ of biofilm formation of $C$. krusei and NYS (1000 $\left.\mu \mathrm{g} . \mathrm{mL}^{-1}\right) 40 \%$ of $C$. albicans. Regarding synergistic effect, peptides enhance 7fold the action of ITR to inhibit the biofilm formation of $C$. krusei and $C$. albicans, as well as the degradation of formed biofilm of $C$. krusei. The action mechanism of peptides or in combination with antifungal drugs involved cell wall damage, membrane pore formation, loss of cytoplasmic content, and overproduction of reactive oxygen species (ROS). Docking analysis revealed ionic and hydrophobic interactions between peptides and both drugs, which may explain the synergistic effect. Altogether, our results suggest the high potential of synthetic peptides be employed as adjuvants enhancing the activity of antifungal drugs to overcome the resistance provided by fungal biofilm and decrease the toxicity of drugs.

\section{Introduction}

The fast increase of antimicrobial resistance to drugs on a global scale is driving humanity to a "postantibiotic era" where the available drugs will no longer work ${ }^{1,2}$. In this scenario, infections caused by fungi have gained attention. Annually, there have, 200 million new cases of infections caused by resistant fungi leading to over 1 million deaths ${ }^{3}$. Among the fungi that affect humans, those belonging to Candida genus 6 have a higher prevalence, 7 cases per 100 patients $^{3-5}$.

Candida genera affect debilitated patients, as such transplanted, cancer patients, and immunesuppressed, leading to a bloodstream infection, prolonged hospital stays, and high mortality rates ${ }^{3-5}$. Until 2010, C. albicans carrying resistance to multiple drugs was responsible for at least $60 \%$ of clinical infections ${ }^{3}$. Nowadays this scenario has changed. Today, infections caused by non- $C$. albicans reached $56.5 \%$ of Candida infections. The new cases are divided C. glabrata (33.3\%), C. tropicalis (20.3\%), C. krusei (1.4\%), and $C$. kefyr (1.4\%). Even though this change $C$. albicans still holds the higher number of cases, $43.5 \%$.

Many pathogenic yeasts like Candida ssp. have developed large spectra of resistance mechanisms to drugs. But the most important is the ability to form biofilms. The production of biofilms could increase drug resistance up 1000-fold to conventional drugs compared to free cells ${ }^{7}$. Besides protecting by altering the $\mathrm{pH}$ and osmolarity, preventing the nutrients scarcity, and alleviates mechanical and shear forces the matrix of biofilms boosts the resistance by protecting yeasts cells from drugs and the host's immune response $^{7-10}$. It is not quite clear what are the triggers to the quorum sense gene expression, but it is 
known the composition of the matrix, which is rich in carbohydrates, proteins, lipids, nucleic acids, and water $^{8}$.

To overcome the threat imposed by yeast's resistance to drugs, synthetic antimicrobial peptides (SAMPs) are an alternative either as a new drug to work alone or even as adjuvants enhancing the activity of commercial drugs ${ }^{1,11}$. During the design, SAMPs were programmed to have a positive charge, amphipathic properties, hydrophobic acceptable rates, and no toxicity potential to hosts. Breakthroughs in technologies of chemical synthesis led to reduction of costs for synthesis, high purity, and high amount of SAMPs ${ }^{1}$.

Recently, two synthetic peptides (PepGAT and PepKKA) were reported to strongly inhibit, at low concentrations, the growth of species of the Candida genus ${ }^{12}$. Thus, we reasoned both peptides could be effective against biofilm from the Candida genus, in addition, to develop synergistic effects with drugs that lost activity. Here, the antibiofilm activity and action mechanisms PepGAT and PepKKA against $C$. albicans and $C$. krusei are described and characterized, employing advanced microscopy techniques. Furthermore, the results revealed that the synergistic effects of peptides enhanced the antibiofilm activity of commercial drugs, Nystatin (NYS) and Itraconazole (ITR), which were no longer effective to Candida biofilm.

\section{Methods}

\section{Ethical Statement}

Not applied for this study.

\section{Biological materials}

The clinical isolates of $C$. albicans, $C$. krusei, $C$. parapsilosis were from the laboratory of plant toxins the Department of biochemistry and molecular biology of Federal University of Ceará (UFC), Fortaleza, Brazil.

\section{Peptide synthesis}

The synthetic peptides PepGAT and PepKAA ${ }^{12}$ were chemically synthesized by the company GenOne (São Paulo, Brazil), which analyzed their quality and purity ( $\geq 95 \%)$ by reverse-phase high-performance liquid chromatography (RP-HPLC) and mass spectrometry.

\section{Biological activity}

Antibiofilm and synergisms assays

The effect of PepGAT and PepKAA on the Candida ssp., biofilm formation was evaluated in polystyrene flat-bottom 96-well microtiter plates ${ }^{37}$. The cell suspensions were prepared from yeasts cultured for $18 \mathrm{~h}$ at $37^{\circ} \mathrm{C}$ in the Sabouraud broth. Then, the cell concentration was diluted to $10^{6} \mathrm{cells}^{-1}$ in the growth 
medium. One hundred microliters of the cell suspensions $\left(10^{6}\right.$ cells $\left.\mathrm{mL}^{-1}\right)$ were incubated at $37^{\circ} \mathrm{C}$ for 48 $\mathrm{h}$, in the dark with $100 \mu \mathrm{L}$ of the synthetic peptides at different concentrations $\left(50 \mu \mathrm{g} \mathrm{mL}^{-1}\right)$ in a solution composed of $5 \% \mathrm{DMSO}$ in $0.15 \mathrm{M} \mathrm{NaCl}(\mathrm{DMSO}-\mathrm{NaCl})$. After that, the supernatant was harvested and the wells were washed with sterile $0.15 \mathrm{M} \mathrm{NaCl}$, air-dried for $30 \mathrm{~min}$, and the biofilm formed was stained with an aqueous solution of $0.1 \%(\mathrm{~m} / \mathrm{v})$ crystal violet, for $15 \mathrm{~min}$ at room temperature $\left(24 \pm 2^{\circ} \mathrm{C}\right)$. To remove the unbound crystal violet, the wash was repeated (3x) with sterile $0.15 \mathrm{M} \mathrm{NaCl}$. Finally, $250 \mu \mathrm{L}$ of $95 \%$ $(\mathrm{v} / \mathrm{v})$ ethanol was added to solubilize the bound dye, and absorbance was taken in a microplate reader (BioTekTM ELx800TM, BioTek Instruments, Inc., USA) at a wavelength of $570 \mathrm{~nm}$. The inhibition of biofilm formation was calculated by comparing the absorbance readings of cells treated with synthetic peptides and those obtained from cells treated with DMSO-NaCl solution (negative control), ITR (1000 $\mu \mathrm{g}$ $\left.\mathrm{mL}^{-1}\right)$, and NYS $\left(1000 \mu \mathrm{g} \mathrm{mL}^{-1}\right)$ both used as positive controls.

A second experiment was carried out to evaluate the effect of the peptides on the degradation of the preformed yeast biofilms. So, $200 \mu \mathrm{L}$ aliquots of the cell suspensions $\left(10^{6}\right.$ cells $\mathrm{mL}^{-1}$, prepared as described above) were incubated at $37^{\circ} \mathrm{C}$ for $24 \mathrm{~h}$, in the dark to form the biofilm. Then, the supernatant was aspirated with a micropipette and to remove the planktonic cells. In each well, $100 \mu \mathrm{L}$ of each synthetic peptide ( $50 \mu \mathrm{g} \mathrm{mL}^{-1}$ ) or controls plus $100 \mu \mathrm{L}$ growth medium (Sabouraud broth) were added. The plates were incubated for $24 \mathrm{~h}$ at $37^{\circ} \mathrm{C}$, in the dark. The culture medium was again discarded, and the same procedure described above was used to quantify the biofilm biomass remaining after incubation with the peptide.

The synergism assays were performed between peptides with either antifungals NYS or ITR: The combinations were constituted of each peptide $\left(50 \mu \mathrm{g} \mathrm{mL}^{-1}\right)+\mathrm{NYS}$ or ITR $\left(1000 \mu \mathrm{g} \mathrm{mL}^{-1}\right)$. The control to evaluate the effectiveness of synergism was the activity presented by peptides or drugs alone. After the formulation of combinations, the antibiofilm assays for synergism analyses for Candida ssp., were the same as described above.

\section{Study of mechanisms of action of peptides against biofilms}

Biofilm integrity by scanning electron microscopy (SEM)

Morphological changes in the biofilm of $C$. albicans and $C$. krusei were evaluated by SEM, as previously described by Staniszewska et al. ${ }^{38}$ with modification. For that, biofilms were produced, and the assay was performed as described above (see the Antibiofilm section) but, this time the biofilm was grown on the coverslip (previously treated with $0.1 \%$ gelatin) inside well of six-well plates. After, the biofilm was fixed with fixation buffer [in $1 \%(\mathrm{v} / \mathrm{v})$ glutaraldehyde $+4 \%(\mathrm{v} / \mathrm{v})$ formaldehyde in $0.15 \mathrm{M}$ sodium phosphate buffer at pH 7.0]. Next, treated with $0.2 \%(\mathrm{~m} / \mathrm{v})$ osmium tetroxide for $30 \mathrm{~min}$ in the dark, and successively dehydrated with ethanol concentration $(30,70,100,100$, and 100\% [v/v]) for $10 \mathrm{~min}$ each, after each wash the ethanol was aspirated with an automatic pipette. In the end, final dehydration was carried out with 50/50 ethanol/hexamethyldisilazane (HMDS) for 10 min and lastly with 100\% HMDS. Then, each coverslip was removed from each well and assembled on stubs, and coated with a $20 \mathrm{~nm}$ 
gold layer using positron-emission tomography (PET) coating machine (Emitech-Q150TES, Quorum Technologies, England). Images were made in an FEl Inspect ${ }^{\text {TM }} 50$ scanning electron microscope (Oregon, USA), equipped with a low energy detector (Everhart-Thornley) using acceleration beam voltage of 20,000 $k V$ and 20,000x detector magnification. The treatments for this assay were peptides alone, drugs alone, and solutions made by peptides and drugs.

Biofilm integrity determined by propidium iodide $(\mathrm{PI})$ uptake

The biofilms were produced as described in the biofilm assays and in the SEM microscopy sections. After, peptide-, controls-, and drugs-peptides mixed solution treated biofilm were incubated with $10^{-3} \mathrm{M}$ of propidium iodide $(\mathrm{PI})$, in the dark, at $37^{\circ} \mathrm{C}$ for $30 \mathrm{~min}$. Then, the biofilm-containing coverslips were washed with $0.15 \mathrm{M}$ of $\mathrm{NaCl}$ three times, to remove the unbound $\mathrm{PI}$ and observed under a fluorescent microscope (Olympus System BX 60) with an excitation wavelength of $490 \mathrm{~nm}$ and an emission wavelength of $520 \mathrm{~nm}$.

Overproduction of reactive oxygen species (ROS) by biofilm

The overproduction of ROS was evaluated as described by Dias et al. ${ }^{37}$ with modifications. The biofilms were produced as described in the biofilm assays and in the SEM microscopy sections. After, peptide-, controls-, and drugs-peptides mixed solution treated biofilm were incubated with $10 \mu \mathrm{M}$ of $2^{\prime}, 7^{\prime}$ dichlorofluorescein diacetate (DCFH-DA) at $37^{\circ} \mathrm{C}$ in the dark for $30 \mathrm{~min}$. Then, the biofilm-containing coverslips were washed with $0.15 \mathrm{M}$ of $\mathrm{NaCl}$ three times, to remove the unbound $\mathrm{PI}$ and observed under a fluorescent microscope (Olympus System BX 60) with an excitation wavelength of $488 \mathrm{~nm}$ and an emission wavelength of $525 \mathrm{~nm}$.

\section{Molecular docking of drugs and peptides}

The 3D structures of peptides PepGAT and PepKAA were predicted using the previous methodology established $^{12,39}$. The protonation of the peptides was calculated to $\mathrm{pH} 7.4$ using ProteinPrepare ${ }^{40}$. The 3D structures of NYS and ITR were obtained in the database PubChem with CID 16219709 and 55283, respectively ${ }^{41}$. The protonation of the drugs was adjusted to $\mathrm{pH} 7.4$ in the software Marvin Sketch version 15.6.15. The energy minimization of the peptide and the ligand was carried out in Discovery Studio v. 20.1 and Open Babel version 2.4.0, respectively.

Molecular docking was performed with Autodock Vina, version 1.1.2 $2^{42}$. The Autodock graphical interface, AutoDockTools, version 1.5.6, was used to retain polar hydrogens and add partial charges to the proteins and ligands using the Kollman united charges ${ }^{42}$. The PepGAT and PepKAA were treated as rigid molecules while the NYS and ITR were docked as flexible molecules. The grid box was defined by a $24 \AA$ x $24 \AA$ x $24 \AA$ cube with the peptide in the center. Exhaustiveness was set up to 16, and all other parameters were used as default. After the molecular docking, the calculation of the interactions was carried out with the software Discovery Studio v. 20.1 and the 3D interaction representations were realized in Pymol v. 1.3. 


\section{Hemolytic assay}

The hemolytic activity of synthetic peptides, NYS, ITR, and combination by then was tested in A, B, and Otypes of human red blood cells (HRBC), according to Souza et al. ${ }^{12}$. The combined solutions of peptides and either NYS or ITR were the same as used in synergism assays. The HRBCs from A, B, and 0 were provided by the Ceará Hematology and Hemotherapy Center (Brazil).

The blood was collected in the presence of heparin $\left(5 \mathrm{IU} \mathrm{mL}^{-1}\right)$, centrifuged at $300 \mathrm{~g}$ for $5 \mathrm{~min}$ at $4^{\circ} \mathrm{C}$, and gently dissolved in sterile $0.15 \mathrm{M} \mathrm{NaCl}$. The blood was washed three times with $0.15 \mathrm{M} \mathrm{NaCl}$ and diluted to a concentration of $2.5 \%$ in $0.15 \mathrm{M} \mathrm{NaCl}$ used in the assay. One hundred microliters of each blood type were incubated, individually, with solutions of synthetic peptides $\left(50 \mu \mathrm{g} \mathrm{mL}^{-1}\right)$, NYS $\left(1000 \mu \mathrm{g} \mathrm{mL}^{-1}\right)$, ITR $\left(1000 \mu \mathrm{g} \mathrm{mL}^{-1}\right)$, the solution made by peptides and drugs, DMSO-NaCl, and $0.1 \%(\mathrm{v} / \mathrm{v})$ Triton X-100 (the positive control for hemolysis) for $30 \mathrm{~min}$ at $37^{\circ} \mathrm{C}$, followed by centrifugation ( $300 \mathrm{~g}$ for $5 \mathrm{~min}$ at $4^{\circ} \mathrm{C}$ ). Then, the supernatants were collected and transferred to 96-well microtiter plates. Hemolysis (\%) was calculated by measuring the supernatant absorbance at $414 \mathrm{~nm}$ using an automated absorbance microplate reader. Negative $(0 \%)$ and positive $(100 \%)$ hemolysis were determined by treating HRBCs with $5 \%$ DMSO in $0.15 \mathrm{M} \mathrm{NaCl}$ (vehicle for peptides) and $0.1 \%(\mathrm{v} / \mathrm{v})$ Triton X-100, respectively. The hemolysis was calculated by the equation: [( Abs $_{414 \mathrm{~nm}}$ of HRBC treated with peptides-Abs $\mathrm{A}_{414 \mathrm{~nm}}$ HRBCs treated with $0.15 \mathrm{M} \mathrm{NaCl}) /\left[\left(\mathrm{Abs}_{414 \mathrm{~nm}}\right.\right.$ of HRBCs treated with $0.1 \%$ TritonX-100-Abs ${ }_{414 \mathrm{~nm}}$ of HRBCs treated with 0.15 $\mathrm{M} \mathrm{NaCl})] \times 100$.

\section{Statistical analysis}

All the experiments were performed three times, and the statistics were expressed as the mean \pm standard error. The data were submitted to ANOVA followed by the Tukey test, using GraphPad Prisma 5.01, with the significance of $p<0.05$.

\section{Results}

\section{Antibiofilm activity of peptides and synergistic effect with antifungal drugs}

The peptides $\left(50 \mu \mathrm{g} . \mathrm{mL}^{-1}\right)$ presented different behaviors toward the biofilm of Candida ssp (Fig. 1). Either the peptides, antifungal drugs, or combinations had any activity against the biofilm of $C$. parapsilosis or $C$. tropicalis (data not shown). The first assay was done to evaluate the ability of peptides to inhibit the biofilm formation of $C$. krusei and $C$. albicans (Fig. $1 \mathrm{~A}$ and B). To $C$. krusei both peptides barely reach $10 \%$ of inhibition. ITR and NYS reached, respectively, 20 and $0 \%$ of inhibition of biofilm formation by C. krusei (Fig. 1A). In contrast, the combinations of both PepGAT (50 $\left.\mu \mathrm{g} \mathrm{mL}^{-1}\right)+$ ITR (1000 $\left.\mu \mathrm{g} \mathrm{mL}^{-1}\right)$ and PepKAA $\left(50 \mu \mathrm{g} \mathrm{mL}^{-1}\right)+$ ITR $\left(1000 \mu \mathrm{g} \mathrm{mL}^{-1}\right)$ led to an inhibition, respectively, of 80 and $76 \%$ of $C$. krusei biofilm (Fig. 1A). The combination of peptides with NYS was not effective. Regarding $C$. albicans NYS, PepGAT, and PepKAA inhibited, respectively, 40,10 , and $20 \%$ of biofilm formation. An interesting result was the synergism found in the combinations made by PepGAT + ITR, PepGAT + NYS, 
and PepKAA + NYS that inhibited, respectively, $40 \%, 95 \%$, and $98 \%$ the biofilm formation of $C$. albicans (Fig. 1B).

Regarding the degradation of formed biofilm, no results were found to $C$. albicans, C. parapsilosis, and $C$. tropicalis (data not shown), only toward C. krusei (Fig. 1C). ITR, PepGAT, and PepKAA alone did reduce biomass of preformed biofilm of $C$. krusei (Fig. 1C). In contrast, NYS was able to reduce in $20 \%$ the biomass of $C$. albicans preformed biofilm (Fig. 1C). Except for the PepGAT + NYS combination that did not show a significant difference in biomass reduction, PepGAT + ITR, PepKAA + ITR, and PepKAA + NYS reduced in, respectively, 50\%, 30\%, and $15 \%$ the preformed biofilm of C. albicans (Fig. 1C).

\section{Biofilm integrity and ROS overproduction}

To evaluate how peptides alone and the combination with drugs affect the membrane of cells composing the biofilm, fluorescence microscopy was employed (Figs. 2-5). Propidium iodide (PI) is a fluorophore that binds to DNA releasing red fluorescence. However, PI only crosses the damaged cell membrane, healthy membrane blocks the movement of PI leading to no fluorescence at all. As expected, all controls made by DMSO-NaCl solution (the vehicle of peptides) presented no fluorescence, suggesting the membranes have no type of more formed (Figs. 2-5). Another interesting result was that, alone, none of the drugs (NYS and ITR) produced any kind of fluorescence (Figs. 2-5).

Regarding the synthetic peptides, PepGAT did induce fluorescence in all treatments either in the inhibition of biofilm formation although at different intensities (Figs. 2-4) and degradation of preformed biofilm (Fig. 5). The PepKAA peptides presented a different behavior. In the case of the inhibition of biofilm formation by $C$. krusei, PepKAA alone was not able to induce damage in the membrane to allow $\mathrm{PI}$ to pass by the membrane and emits fluorescence (Fig. 2). In contrast, PepKAA induced the fluorescence in the inhibition of biofilm formation by $C$. albicans (Fig. 4). In the case of combinations made by peptides and antifungals drugs, all of them presented fluorescence to some extent (Figs. 2-5). This is an interesting result for three reasons: 1 ) drugs alone did not show any fluorescence (Figs. 2-5); 2) in the case of PepKAA, which did not show fluorescence, the combination with ITR lead to a release of fluorescence (Figs. 2 and 3) in some cases, such as PepGAT+ITR (Figs. 3 and 5) fluorescence produced by the combination was higher than that produced by drugs alone, suggesting a bigger number of cell damage in the combination.

The experiments to evaluate the ROS overproduction in the biofilms revealed a different pattern than $\mathrm{PI}$ experiments. All controls either positive or negative did not produce any type of fluorescence indicating no ROS production (Figs. 2-5). In the inhibition of biofilm formation of $C$. krusei, both peptides induced ROS production at different intensities, as revealed by fluorescence. In this case, the cells treated with PepGAT were brighter than the ones produced by PepKAA. Following this pattern, the combinations made to inhibit the biofilm formation by $C$. krusei produced only a slight fluorescence, indicating a low level of ROS was produced (Fig. 2). In the inhibition of biofilm formation by C. albicans to ROS production, only a slight production of ROS was indicated by a faint fluorescence in the treatment with PepKAA (Fig. 4). In contrast, brighter fluorescence indicates a higher production of ROS in both PepGAT alone and 
combination with ITR in the degradation of preformed biofilm of $C$. krusei(Fig. 5), suggesting that the ROS overproduction is, indeed, an important mechanism to degrade the biofilm.

\section{Scanning electron microscopy (SEM) analyses of biofilm}

SEM images revealed severe that all control made with DMSO-NaCl solution the biofilm was in a good spherical shape, with no cracks or damage, and cells were seen with no visible damage to membrane or cell wall (Figs. 6-8). The SEM analysis revealed that the cells involved in biofilm formation (Figs. 6 and 7) and preformed biofilm (Fig. 8) were not affected by the treatment with either ITR or NYS both at $1000 \mu \mathrm{g}$ $\mathrm{mL}^{-1}$.

SEM analysis strength the damages revealed by fluorescence microscopy in Candida cells (Figs. 2-5), which were confirmed by SEM analysis (Fig. 6-8). To inhibit the formation of $C$. krusei PepGAT induced several damages to cells. It was possible to see depression-like cavity on cells (Fig. 6, PepGAT and PepKAA Panels, white dashed circle) indicating damage to the cell wall, small blebs, new buds, scars on new buds and cells, and rings of truncated bud scars in the treatment with both peptides (Fig. 6, white arrowheads). In both treatments with peptides, cells present high levels of wrinkles and scars all over the structure. Additionally, in both treatment with peptides alone is possible to see a lack of constriction in the solid point of the septum (Fig. 6, white open arrows). In contrast to what was seen in the treatment with drugs alone, the combination of peptides and drugs lead to several damages to cells and thus inhibit biofilm formation. In both cases, many cells presented depression-like cavities (Fig. 6, PepGAT+ITR and PepKAA+ITR panels, white dashed circle) indicating damage to the cell wall, in addition to alterations in cell shape, wrinkles and scars all over the structure, small blebs, new buds, scars on new buds and cells, and rings of truncated bud scars in the treatment with both peptides (Fig. 6, white arrowheads), and no presence of a solid point in septum junction (Fig. 6, white open arrows).

SEM analysis revealed a different pattern in the inhibition of biofilm formation of $C$. albicans (Fig. 7). The controls DMSO-NaCl solution, ITR, and NYS at $1000 \mu \mathrm{g} \mathrm{mL}^{-1}$ showed no significant alteration on $C$. albicans cells (Fig. 7). Treatment with PepGAT induced small blebs, new buds, scars on new buds and cells (Fig. 7, white arrowheads). In contrast, the treatment with PepKAA is possible to damage all cells. Cells stick together but all the present bad conformation and with pieces of other cells on the top of them (Fig. 7, panel PepKAA). SEM analysis revealed that the combination of PepGAT + ITR killed almost all cells (Fig. 7), and the leftovers are completely damaged unable to form biofilm. The combination made of PepKAA + ITR is far less effective than PepGAT + ITR causing scars and wrinkles on cells, abnormal shape, and it is also possible to see the presence of small blebs, new buds, scars on new buds and cells, and rings of truncated bud scars in the treatment with both peptides (Fig. 7, white arrowheads). The combinations of both peptides + NYS were most efficient than with combination with ITR. In both cases all cells were dead, and it was only found isolated cell completely damaged, with the signal of loss of internal content and with no ability to form biofilm at all (Fig. 7, PepGAT and PepKAA panels). 
In the degradation of $C$. krusei preformed biofilm, SEM analysis of ITR-treated biofilm revealed no damage at all on the biofilm (Fig. 8). In the treatment with peptides alone or combination with ITR the biofilm constituting cells presented damage to the cell wall, loss of internal content, small blebs, new buds, many scars, and wrinkles on new buds and cells (Fig. 8 white arrowheads), and rings of truncated bud scars in the treatment with both peptides (Fig. 8, white open arrows).

\section{Hemolytic Assay}

As shown in a previous study (Souza et al., 2020) the synthetic peptides had no hemolytic activity against any human blood type tested (Table 1), even at $50 \mu \mathrm{g} . \mathrm{mL}^{-1}$. In contrast, NYS at $1000 \mu \mathrm{g} . \mathrm{mL}^{-1}$ caused $100 \%$ hemolysis in all human blood types and ITR at $1000 \mu \mathrm{g} \cdot \mathrm{mL}^{-1}$ caused 80,75 , and $69 \%$ of hemolysis, respectively, to Type-A, B, and $O$ of red blood cells (Table 1 ).

In general, the combination of synthetic peptides with antifungal drugs decreased their hemolytic effect (Table 1). The combination of PepGAT with NYS resulted in a hemolytic effect of 54,43 , and $12 \%$, respectively, to Type-A, B, and $O$ of red blood cells, and combination of PepGAT with ITR caused in 17, 45, and $43 \%$ of hemolysis, respectively, to Type-A, B, and $O$ of red blood cells (Table 1 ). The combination of PepKAA with NYS hemolyzed 15,10 , and $21 \%$, respectively, of Type-A, $B$, and 0 of red blood cells, whereas the combination of PepKAA with ITR 21,34, $12 \%$, respectively, of Type-A, B, and $O$ of red blood cells (Table 1).

\section{Molecular docking between peptides and drugs}

PepGAT interacts with ITR and NYS with a score of $-4.7 \mathrm{kcal}^{\mathrm{mol}}{ }^{-1}$ (Fig. $9 \mathrm{~A}$ and B). The amino acid residues $\mathrm{Gly}^{1}, \mathrm{Ala}^{2}$, and $\mathrm{Asn}^{8}$ of PepGAT establish Van der Walls interactions with ITR, while the $\mathrm{Arg}^{5}$ residue establishes 4 Pi-Alkyl interactions with the dichlorophenyl (4.3 $\AA$ ), triazole ( $4.7 \AA)$, methoxyphenyl (4.9), and piperazine groups ( $4.2 \AA)$. $\| \mathrm{e}^{4}$ and $\mathrm{Ala}^{6}$ residues of PepGAT interact through Pi-Alkyl interactions with the chlorophenyl (3.6 $⿱$ ) and phenyl (3.5 $\AA$ ) groups of ITR, respectively (Fig. 9A and C). The interaction of PepGAT with NYS is through hydrogen bonds with residues $\operatorname{Asn}^{8}(1.9 \AA)$, Ser ${ }^{9}(2.7 \AA)$, and $\operatorname{Arg}^{10}(2.0 \AA)$, as well as through van der Walls interactions with residues $\mathrm{Gly}^{1}$, $\mathrm{Il}^{4}, \mathrm{Arg}^{5}$, and $\mathrm{Val}^{7}$ (Fig. 9B and D).

PepKAA showed a docking score of -5.8 and $-5.4 \mathrm{kcal}^{\mathrm{mol}}{ }^{-1}$ with the drugs ITR and NYS, respectively (Fig. 9E and F). PepKAA-ITR complex is supported by Pi-Alkyl interaction of $\mathrm{Arg}^{5}$ and $\mathrm{Lys}^{1}$ interactions with the dichlorophenyl and triazole groups of ITR. Lys ${ }^{7}$ from PepKAA performs three Pi-Cation interactions with piperazine (5.0 ̊)), phenyl (3.8 $\AA$ ), and triazolone (3.7 ̊̊) groups from ITR. PepKAA residues Asn ${ }^{4}, \mathrm{Tyr}^{8}$, and Phe ${ }^{9}$ interact with ITR through Pi-Sigma (2.5 ̊), Pi-Pi stacked (4.1 Å) and van der Walls interactions, respectively (Fig. 9E and G). In turn, the interaction of PepKAA with NYS is supported by hydrogen bonds of residues $\operatorname{Arg}^{5}(2.0 \AA)$ and $\operatorname{Tyr}^{8}(2.9 \AA)$ of PepKAA, as well as van der Walls interactions with residues $\mathrm{Asn}^{4}$ and $\mathrm{Phe}^{9}$. It was also noted 2 Pi-Alkyl interactions between the residues Lys $^{1}(4.8 \AA)$ and Ala $^{2}(4.3 \AA)$ of the peptide with NYS (Fig. 9F and H). 


\section{Discussion}

Fungal infection caused by yeast from Candida species poses a critical problem in the healthcare field worldwide leading to elevated mortality rates and high costs with medical care for hospitalized patients and governments ${ }^{13,14}$. High mortalities rates caused by Candida species are associated with opportunistic invasive systemic infections, septicemia, and nosocomial bloodstream infections ${ }^{10,15}$.

Even though new antifungal drugs have been developed, mortality rates continue to increase suggesting these new drugs have not improved the treatment of infection caused by Candida species due to high resistance levels they acquired as a result of long-term use by patients ${ }^{10,16}$. The drug-resistant $C$. albicans is the most serious threat to human health worldwide. It is responsible for a higher number of infections caused by Candida species in patients that are immunocompromised, HIV positive, and intensive care unit patients ${ }^{9,17}$. Aware of $C$. albicans infection, there was an increase of infection caused by nonalbicans yeasts. Among those, $C$ krusei have gained attention because of two reasons: 1 ) increase of infection caused by $C$. krusei; and 2) the development by $C$. krusei of multiple resistance to antifungal drugs $^{18-20}$.

Both $C$. albicans and $C$. krusei have developed resistance to many antifungal drugs such as azoles (ITR), echinocandins, polyenes (NYS), among others ${ }^{18}$. Overall, the mechanisms of resistance developed by yeasts involve, overexpression or alteration of the target, development of efflux pumps to remove the excess of drugs of cytoplasm, modification of the drug, and biofilm production 1,18,21,22.

Biofilm is a great resistance structure. However, not all yeasts on Candida genera could produce it but $C$. albicans and $C$. rrusei $^{8}$. The biofilm production by Candida provides a different behavior compared to planktonic life. For example, cells living in the biofilm community can attach irreversibly to any surface, inert material, living tissue, medical devices (e.i., protheses and cardioverter defibrillators), in addition, to increase the expression of virulent factors, and higher resistance to antifungal drugs ${ }^{1,8}$. Based on that, biofilm formation is a serious threat to overcome.

The treatment of infection by Candida ssp., in a planktonic lifestyle, is already hard, the production of biofilm makes this worse. What is known is that antifungal drugs are no longer that effective as expected as showed here (Fig. 1). So, SAMPs are an alternative solution to this problem ${ }^{1}$. Bioinspired SAMPs using carry the best features of the natural AMPS with very low or even no toxicity ${ }^{23,24}$. PepGAT and PepKAA are both synthetic peptides designed by Souza et al. ${ }^{12}$ using a chitinase sequence from NCBI. During the design, in silico analyses, it was predicted that both synthetic peptides could have antibiofilm activity ${ }^{12}$. For both peptides, this was indeed confirmed. PepGAT presented antibiofilm activity against the Salmonella enterica biofilm and PepKAA presented activity against $C$. krusei biofilm ${ }^{12}$. In that study, we have shown PepKAA reduced in $40 \%$ the preformed biofilm of $C$. krusei, which resulted later confirmed here (Fig. 1C). This concentration is at least 1.5-fold lower concentration than other synthetic peptides. 
The effect of synthetic peptides has been already tested toward biofilms. For instance, the synthetic peptides KU4 $\left(96 \mu \mathrm{g} \mathrm{mL}^{-1}\right)$, uperin $3.6\left(96 \mu \mathrm{g} \mathrm{mL}^{-1}\right)$, upn-lys4 $\left(96 \mu \mathrm{g} \mathrm{mL}^{-1}\right)$, upn-lys5 $\left(192 \mu \mathrm{g} \mathrm{mL}^{-1}\right)$, and upn-lys6 $\left(96 \mu \mathrm{g} \mathrm{mL}^{-1}\right)$ reduced the viability of the biofilm of $C$. albicans only in $20,35,15,40$, and $30 \%$, respectively ${ }^{25}$. In the case of $C$. krusei the synthetic peptide VLL-28 at $72 \mu \mathrm{g} \mathrm{mL}^{-1}$ reduced the viability of C. krusei biofilms by $35 \%{ }^{26}$. Paulone et al. ${ }^{27}$ reported a peptide that presented an $\mathrm{IC}_{50}$ value against $C$. albicans biofilm of $126 \mu \mathrm{g} \mathrm{mL}^{-127}$, a concentration almost 3 times higher than that of PepKAA with the same activity. In addition, to this result, here PepKAA has inhibition in $30 \%$ and $45 \%$ of the biofilm formation of $C$. krusei and $C$. albicans (Fig. 1). In our previous work, PepGAT was not effective towards Candida biofilms and this result was confirmed here (Fig. 1).

Compared to above mentioned synthetic peptides, the antibiofilm activity presented by PepKAA is quite interesting given the low concentration. However, for practical application, the results are not that interesting. Based on the experience of our research group about the synergism of synthetic peptides with antifungal drugs ${ }^{28,29}$, we reasoned these peptides could improve the activity of commercial antifungal drugs that struggle to treat fungal infection supported by biofilm formation.

In previous studies, our research group has acquired experience in the synergistic effect of synthetic peptides with drugs presenting low effectiveness ${ }^{28,29}$. First, it was shown by Lima et al. ${ }^{28}$ that synthetic

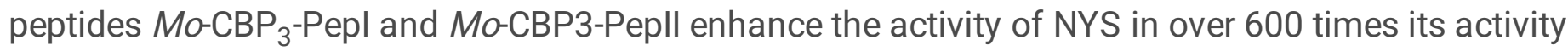
towards planktonic cells of $C$. albicans. In a second study, Souza et al. ${ }^{29}$ reported that six synthetic peptides presented synergistic effects with griseofulvin toward dermatophytes. It is important to notice that griseofulvin alone has no activity against dermatophytes. Here, the interesting and pioneer point of this study is the synergistic effect of synthetic peptides with two antifungal drugs from different groups, ITR (azole) and NYS (polyene) toward Candida biofilms.

The synergistic effect found here were: (1) PepGAT + ITR and PepKAA ITR inhibiting, respectively, 84 and $79 \%$ of the biofilm formation of $C$. krusei (Fig. 1A); (2) the combination of NYS with PepGAT and PepKAA that inhibit in 97 and $98 \%$ the biofilm formation by C. albicans (Fig. 1B); (3) the synergism of PepGAT and ITR that degraded in $55 \%$ the biofilm of $C$. krusei (Fig. 1C). In addition, it was shown by SEM and fluorescence microscopy how these combinations worked together to induce damages in the cells to prevent or degrade biofilm formation.

Fluorescence and SEM analysis brought to light the mechanisms behind revealed lethal damage of those combinations to Candida biofilms. The combinations lead to pore formation in both Candida cells involved in the formation or already formed biofilm. Souza et al. ${ }^{12}$ had shown PepGAT and PepKAA can form pores on $C$. albicans and $C$. krusei membranes, the result later confirmed here. Interestingly, in some cases, the combinations of peptides with the drug (PepGAT + ITR, Fig. 3) lead to a higher level of fluorescence than molecules alone. Fluorescence analyses revealed an interesting result. In some cases, the combinations of peptides with antifungal drugs lead to an overproduction of ROS (Fig. 2 panels PepGAT + ITR and PepKAA + ITR and Fig. 3 PepGAT + ITR). It is interesting that ROS overproduction was 
all in the combinations of either PepGAT or PepKAA with ITR and presented the best results even to inhibit the formation of biofilm (Fig. 1A) or degrade preformed biofilm (Fig. 1C).

ROS are important signaling molecules to any type of life. This is statement is not different from biofilm formation. ROS is important to biofilm biogenesis, development, formation, the genetic variability of cells $^{30}$. However, the line of benefits and lethal effects of ROS is tiny and easy to cross. A slight unbalance in ROS levels could lead to ROS accumulation, which is lethal because they inactivate vital molecules such as carbohydrates, nucleic acids, proteins, and lipids, triggering programmed cell death $(P C D)^{31}$. Overall, the mechanism behind the overproduction of ROS by peptides is hard to describe. Nevertheless, here it was shown the high level of ROS on biofilms was induced by combinations made of peptides and antifungal drugs, which promotes an unbalance in ROS levels on biofilms and consequently death.

Supporting the results of fluorescence microscopy, SEM analysis revealed the combinations of peptides and drugs lead to several damages such as depression-like cavity indicating damage to the cell wall, in addition to alterations in cell shape, wrinkles and scars all over the structure, small blebs, new buds, scars on new buds and cells, and rings of truncated bud scars in the treatment with both peptides, and no presence of a solid point in septum junction (Figs. 6-8). Souza et al. ${ }^{12}$ have proved experimentally PepGAT and PepKAA are chitin-binding peptides, which is expected since peptides are designed from a chitinase sequence. So, chitin is the main component of the Candida cell wall, by interacting with it, peptides could lead to damages on the cell wall (Figs. 6-8) and somehow enhance the effect of antifungal drugs.

There are two hypotheses to explain the improvement of antifungal drugs by peptides. The first one is directly related to the mechanism of action ITR and NYS. Although being of different classes ITR and NYS have the same target. ITR interacts with the enzyme lanosterol 14a-demethylase to inhibit the ergosterol biosynthesis, and NYS interacts with the ergosterol in the membrane causing an unbalance in the membrane ${ }^{32,33}$. By interacting with chitin in the cell wall, both PepGAT and PepKAA, cause a rupture in the cell wall (Figs. 6-8) facilitating the access of lanosterol 14a-demethylase and ergosterol, respectively, by ITR and NYS and thus enhancing their activity. The second explanation is based on the peptides attacking directly the membrane, as revealed by fluorescence microscopy (Figs. 2-5). During the treatment of candida with combinations made by peptides and antifungal drugs, membranes are double attacked. Peptides attack the membrane to form pores and drugs attack their target in the membranes.

In addition, our pioneer work showed by molecular docking, both peptides interact with both drugs with a low score (Fig. 9). Very likely, this lower interaction allowed the better synergistic effect between molecules favoring the action of both on the membranes ${ }^{29}$. The complexes made by peptides and drugs were supported by polar interactions (hydrogen bonds) and hydrophobic interactions (mainly aromaticaromatic interactions). 
Both ITR and NYS have many collateral effects. ITR may cause vomiting, diarrhea, headache, and dizziness. Besides these collateral effects, cardiotoxicity and hypertension were attributed to ITR use ${ }^{34}$. Regarding NYS the collateral effects are poor taste (the incidence was $61.5 \%$ in one study) 28 and gastrointestinal adverse reactions, including vomiting, nausea, diarrhea, anorexia, and abdominal pain $^{35,36}$. Here, it was showed the toxicity of ITR and NYS to human erythrocytes (Table 1). The interesting result was that the association of peptides with antifungal drugs reduced their toxicity in human erythrocytes. For example, NYS alone caused hemolysis of $100 \%$ on type- 0 blood. The solution made by PepGAT + NYS and PepKAA + NYS caused hemolysis, respectively, of 12 and $21 \%$ in type-O blood. This is a reduction of 8.3- and 4.7-fold in the toxicity of NYS to type-O blood cells. In all treatments made with combinations, were found a reduction in toxicity of antifungal drugs, at least 2 -fold. The reduction of drugs' toxicity by interaction with peptides makes them great for application as adjuvants of these drugs because peptides enhanced their activity toward biofilm and, at the same, reduce their toxicity.

Souza et al. ${ }^{12}$ suggested that the hydrophobic interactions, revealed by docking between peptides and griseofulvin, may be involved in the reduction of its toxicity erythrocytes. That is simple. Hemolytic activity of drugs is driven by hydrophobic interaction between drug and membrane of erythrocytes. The establishment of hydrophobic interactions with drugs, peptides prevent the hemolytic effect of the drug ${ }^{12}$. If we think in the same way. Here was shown that PepGAT and PepKAA establish many hydrophobic interactions with both ITR and NYS, and this is associated with a reduction of both drugs' toxicity to human erythrocytes (Table 1).

\section{Conclusion}

Here is a pioneer study showing the activity, action mechanism, and synergistic effects of two synthetic peptides (PepGAT and PepKAA) with NYS and ITR against biofilms of $C$. albicans and $C$. krusei. In the best combinations, peptides enhanced the antibiofilm activity of both drugs at least five-fold and reduced up to ten-fold their toxic effect against red blood cells. Altogether, our results strongly suggest that PepGAT and PepKAA have a high potential to be adjuvants to enhance the activity of antifungal drugs that are almost useless toward biofilms.

\section{Declarations}

\section{Funding and Acknowledgments}

This work was supported by grants from the following Brazilian agencies: Conselho Nacional de Desenvolvimento Científico e Tecnológico; Coordenação de Aperfeiçoamento de Pessoal de Nível Superior (CAPES); Fundação Cearense de Apoio ao Desenvolvimento Científico e Tecnológico (FUNCAP). A special thanks to CAPES for providing the grant for postdoctoral position for Pedro F. N. Souza. We are also grateful to the central analytical facilities of UFC, Brazil. 


\section{Credit Author Statement:}

Conceptualization: L.P.B., and P.F.N.S.

Data curation: L.P.B., A.F.B.S., J.L.A., N.A.S.N., C.R.A., R.G.G.S., and P.F.N.S.

Formal analysis: C.D.T.F., J.T.A.O., and P.F.N.S.

Funding acquisition: C.D.T.F., and J.T.A.O.

Methodology: L.P.B., A.F.B.S., J.L.A., N.A.S.N., M.O.B., R.G.G.S., and P.F.N.S.

Resources: C.D.T.F., and J.T.A.O.

Supervision: P.F.N.S.

Writing original draft: M.O.B., C.R.A., and P.F.N.S.

Writing, review, and editing: P.F.N.S.

\section{Conflict of interest}

All authors declare no conflict of interest.

\section{References}

1. Lima, P. G., Oliveira, J. T. A., Amaral, J. L., Freitas, C. D. T. \& Souza, P. F. N. Synthetic antimicrobial peptides: Characteristics, design, and potential as alternative molecules to overcome microbial resistance. Life Sci, 278, 119647 (2021).

2. Biggest Threats and Data | Antibiotic/Antimicrobial Resistance | CDC. https://www.cdc.gov/drugresistance/biggest-threats.html.

3. M, S. B, P. \& C, L.-F. Antifungal drug resistance among Candida species: mechanisms and clinical impact., 58 (Suppl 2), 2-13 (2015).

4. GD, B. et al. Hidden killers: human fungal infections.Sci. Transl. Med.4, (2012).

5. Morgan, J. et al. Excess Mortality, Hospital Stay, and Cost Due to Candidemia: A Case-Control Study Using Data From Population-Based Candidemia Surveillance. Infect. Control Hosp. Epidemiol, 26, 540-547 (2005).

6. Fu, J. et al. Epidemiology of Candida albicans and non-C.albicans of neonatal candidemia at a tertiary care hospital in western China. BMC Infect. Dis, 17, 329 (2017).

7. De La Fuente-Núñez, C., Cardoso, M. H., De Souza Cândido, E., Franco, O. L. \& Hancock, R. E. W. Synthetic antibiofilm peptides. Biochim. Biophys. Acta - Biomembr, 1858, 1061-1069 (2016).

8. Cavalheiro, M. \& Teixeira, M. C. Candida Biofilms: Threats, Challenges, and Promising Strategies. Front. Med, 5, 28 (2018). 
9. Costa-de-Oliveira, S. \& Rodrigues, A. G. Candida albicans Antifungal Resistance and Tolerance in Bloodstream Infections: The Triad Yeast-Host-Antifungal.Microorganisms8, (2020).

10. Marak, M. B. \& Dhanashree, B. Antifungal susceptibility and biofilm production of candida spp. Isolated from clinical samples. Int. J. Microbiol. 2018, (2018).

11. Mohamed, M. F., Abdelkhalek, A. \& Seleem, M. N. Evaluation of short synthetic antimicrobial peptides for treatment of drug-resistant and intracellular Staphylococcus aureus. Sci. Reports 2016, 61 6, 114 (2016).

12. Souza, P. F. N. et al. Synthetic antimicrobial peptides: From choice of the best sequences to action mechanisms., 175, 132-145 (2020).

13. S, N. et al. Fungal vaccines, mechanism of actions and immunology: A comprehensive review. Biomed. Pharmacother, 109, 333-344 (2019).

14. Pristov, K. E. \& Ghannoum, M. A. Resistance of Candida to azoles and echinocandins worldwide. Clin. Microbiol. Infect, 25, 792-798 (2019).

15. T, S. et al. Antifungal susceptibility trend and analysis of resistance mechanism for Candida species isolated from bloodstream at a Japanese university hospital. J. Infect. Chemother, 25, 34-40 (2019).

16. N, P., A, B. \& R, K., S, N. \& Species distribution and drug susceptibility of candida in clinical isolates from a tertiary care centre at Indore. Indian J. Med. Microbiol, 32, 44-48 (2014).

17. S, A., M, C. \& L, M., S, S., M, G. \& Candidemia and invasive candidiasis in adults: A narrative review. Eur. J. Intern. Med, 34, 21-28 (2016).

18. AT, J., OM, J. A., CH, P. \& S. \& Update on Candida krusei, a potential multidrug-resistant pathogen. Med. Mycol, 59, 14-30 (2021).

19. F, C. et al. Mechanism of Antifungal Activity by 5-Aminoimidazole-4-Carbohydrazonamide Derivatives against Candida albicans and Candida krusei. Antibiot. (Basel, Switzerland), 10, 1-13 (2021).

20. TTH, D. et al. Interaction Between Dendritic Cells and Candida krusei $\beta$-Glucan Partially Depends on Dectin-1 and It Promotes High IL-10 Production by T Cells.Front. Cell. Infect. Microbiol.10, (2021).

21. Orozco, A. S. et al. Mechanism of Fluconazole Resistance in Candida krusei. Antimicrob. Agents Chemother, 42, 2645 (1998).

22. Guinea, J., Sánchez-Somolinos, M., Cuevas, O., Peláez, T. \& Bouza, E. Fluconazole resistance mechanisms in Candida krusei: The contribution of efflux-pumps. Med. Mycol, 44, 575-578 (2006).

23. Lata, S., Mishra, N. K. \& Raghava, G. P. S. AntiBP2: improved version of antibacterial peptide prediction. BMC Bioinformatics, 11 Suppl (1), S19 (2010).

24. Lata, S., Sharma, B. \& Raghava, G. Analysis and prediction of antibacterial peptides. BMC Bioinformatics, 8, 263 (2007).

25. KY, L. et al. Activity of Novel Synthetic Peptides against Candida albicans.Sci. Rep.5, (2015).

26. Roscetto, E. et al. Antifungal and anti-biofilm activity of the first cryptic antimicrobial peptide from an archaeal protein against Candida spp. clinical isolates. Sci. Reports 2018 81, 8, 1-11 (2018). 
27. Paulone, S. et al. The synthetic killer peptide KP impairs Candida albicans biofilm in vitro. PLoS One, 12, e0181278 (2017).

28. Lima, P. G. et al. Anticandidal activity of synthetic peptides: Mechanism of action revealed by scanning electron and fluorescence microscopies and synergism effect with nystatin. J. Pept. Sci, 113 https://doi.org/10.1002/psc.3249 (2020).

29. PFN, S. et al. Antidermatophytic activity of synthetic peptides: Action mechanisms and clinical application as adjuvants to enhance the activity and decrease the toxicity of Griseofulvin., $63,979-$ 992 (2020).

30. Čáp, M., Váchová, L. \& Palková, Z. Reactive Oxygen Species in the Signaling and Adaptation of Multicellular Microbial Communities. Oxid. Med. Cell. Longev. 2012, 13 (2012).

31. Maurya, I. K. et al. Antifungal activity of novel synthetic peptides by accumulation of reactive oxygen species (ROS) and disruption of cell wall against Candida albicans., 32, 1732-1740 (2011).

32. Borgers, M. \& Van de Ven, M. A. Mode of Action of Itraconazole: Morphological Aspects. Mycoses, 32, 53-59 (1989).

33. AG, D. S. et al. The molecular mechanism of Nystatin action is dependent on the membrane biophysical properties and lipid composition. Phys. Chem. Chem. Phys, 19, 30078-30088 (2017).

34. F, Q. T. et al. Evaluation of efficacy and safety of itraconazole oral solution for the treatment of oropharyngeal candidiasis in aids patients. Braz. J. Infect. Dis, 5, 60-66 (2001).

35. Nystatin Side Effects: Common, Severe, Long Term - Drugs.com. https://www.drugs.com/sfx/nystatin-side-effects.html.

36. Macesic, N., Wingard, J. R. \& NystatinKucers Use Antibiot. A Clin. Rev. Antibacterial, Antifung. Antiparasit. Antivir. Drugs, Seventh Ed.2646-2652(2020).

37. Dias, L. P. et al. RcAlb-Pepll, a synthetic small peptide bioinspired in the $2 S$ albumin from the seed cake of Ricinus communis, is a potent antimicrobial agent against Klebsiella pneumoniae and Candida parapsilosis. Biochim. Biophys. Acta -Biomembr, 1862, 183092 (2020).

38. Staniszewska, M. et al. Candida albicans morphologies revealed by scanning electron microscopy analysis. Brazilian J. Microbiol, 44, 813-821 (2013).

39. Thévenet, P. et al. PEP-FOLD: an updated de novo structure prediction server for both linear and disulfide bonded cyclic peptides. Nucleic Acids Res, 40, W288-93 (2012).

40. Martínez-Rosell, G., Giorgino, T., Fabritiis, G. \& De PlayMolecule ProteinPrepare: A Web Application for Protein Preparation for Molecular Dynamics Simulations. J. Chem. Inf. Model, 57, 1511-1516 (2017).

41. Kim, S. et al. PubChem 2019 update: improved access to chemical data. Nucleic Acids Res, 47, D1102-D1109 (2019).

42. Trott, O. \& Olson, A. J. AutoDock Vina: improving the speed and accuracy of docking with a new scoring function, efficient optimization and multithreading. J. Comput. Chem, 31, 455 (2010). 


\section{Tables}

Table 1. Hemolytic activity of synthetic peptides, antifungal drugs, and their combination toward human red blood cells

\begin{tabular}{|c|c|c|c|}
\hline \multirow[t]{2}{*}{ Peptides/Combinations } & \multicolumn{3}{|l|}{ \% Hemolysis } \\
\hline & Type-A Blood & Type-B Blood & Type-O Blood \\
\hline $0.1 \%$ Triton $\mathrm{X}-100$ & 100 & 100 & 100 \\
\hline DMSO-NaCl Solution & 0 & 0 & 0 \\
\hline NYS $\left(1000 \mu \mathrm{g} \mathrm{mL}^{-1}\right)$ & 100 & 100 & 100 \\
\hline ITR $\left(1000 \mu \mathrm{g} \mathrm{mL}^{-1}\right)$ & 80 & 75 & 69 \\
\hline PepGAT $\left(50 \mu \mathrm{g} \mathrm{mL}^{-1}\right)$ & 0 & 0 & 0 \\
\hline PepKAA $\left(50 \mu \mathrm{g} \mathrm{mL}^{-1}\right)$ & 0 & 0 & 0 \\
\hline $\begin{array}{l}\text { PepGAT }\left(50 \mu \mathrm{g} \mathrm{mL}^{-1}\right)+ \\
\text { NYS }\left(1000 \mu \mathrm{g} \mathrm{mL}^{-1}\right)\end{array}$ & 54 & 43 & 12 \\
\hline $\begin{array}{l}\text { PepGAT }\left(50 \mu \mathrm{g} \mathrm{mL}^{-1}\right)+ \\
\text { ITR }\left(1000 \mu \mathrm{gL}^{-1}\right)\end{array}$ & 17 & 45 & 43 \\
\hline $\begin{array}{l}\text { PepKAA }\left(50 \mu \mathrm{g} \mathrm{mL}^{-1}\right)+ \\
\text { NYS }\left(1000 \mu \mathrm{g} \mathrm{mL}^{-1}\right)\end{array}$ & 15 & 10 & 21 \\
\hline $\begin{array}{l}\text { PepKAA }\left(50 \mu \mathrm{g} \mathrm{mL}^{-1}\right)+ \\
\text { ITR }\left(1000 \mu \mathrm{g} \mathrm{mL}^{-1}\right)\end{array}$ & 21 & 34 & 12 \\
\hline
\end{tabular}

Figures 
A

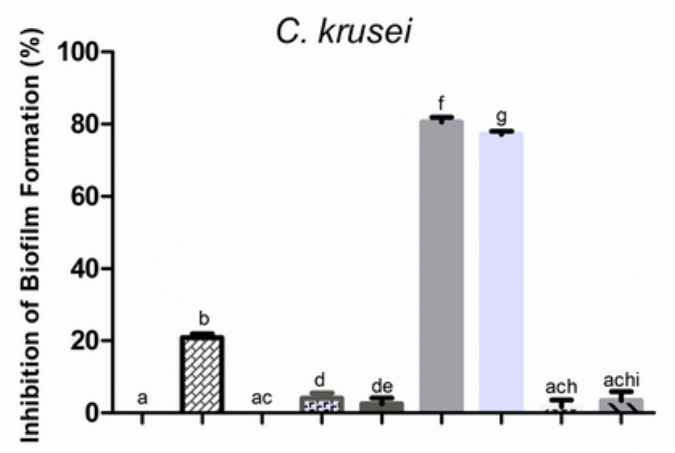

B

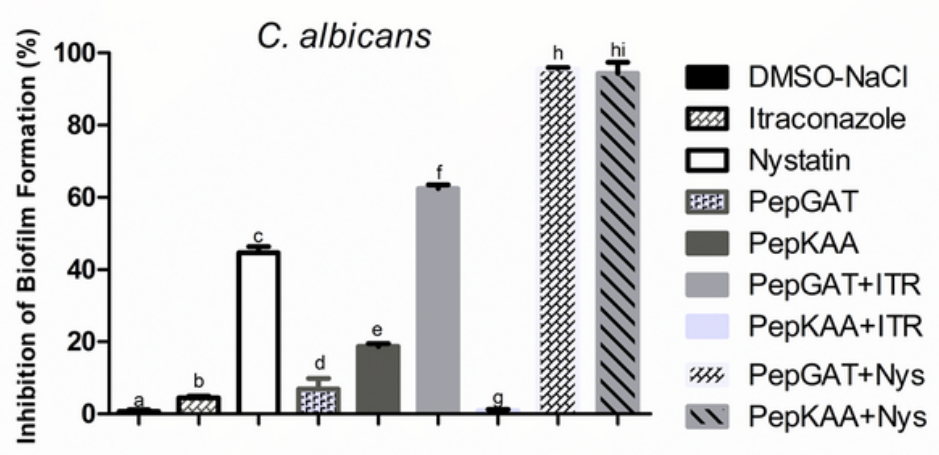

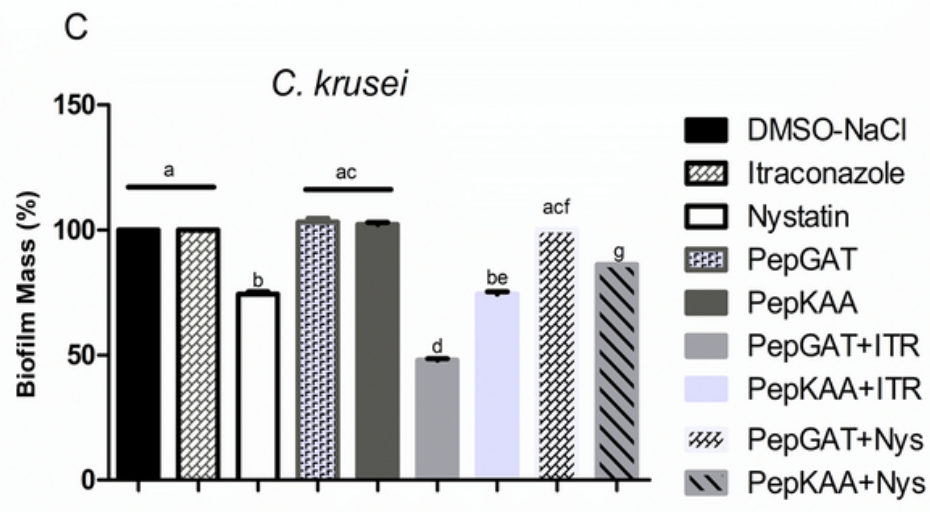

Figure 1

Antibiofilm activity and synergistic effect with Nystatin and Itraconazole of synthetic peptides PepGAT and PepKAA. (A and B) Inhibition of biofilm formation, respectively, of C. krusei and C. albicans. (B) Biofilm degradation of $C$. krusei. All peptides were used at $50 \mu \mathrm{g} \mathrm{mL-1}$. Nystatin and Itraconazole at 1000 $\mu \mathrm{gL}-1$. DMSO-NaCl as a negative control. 


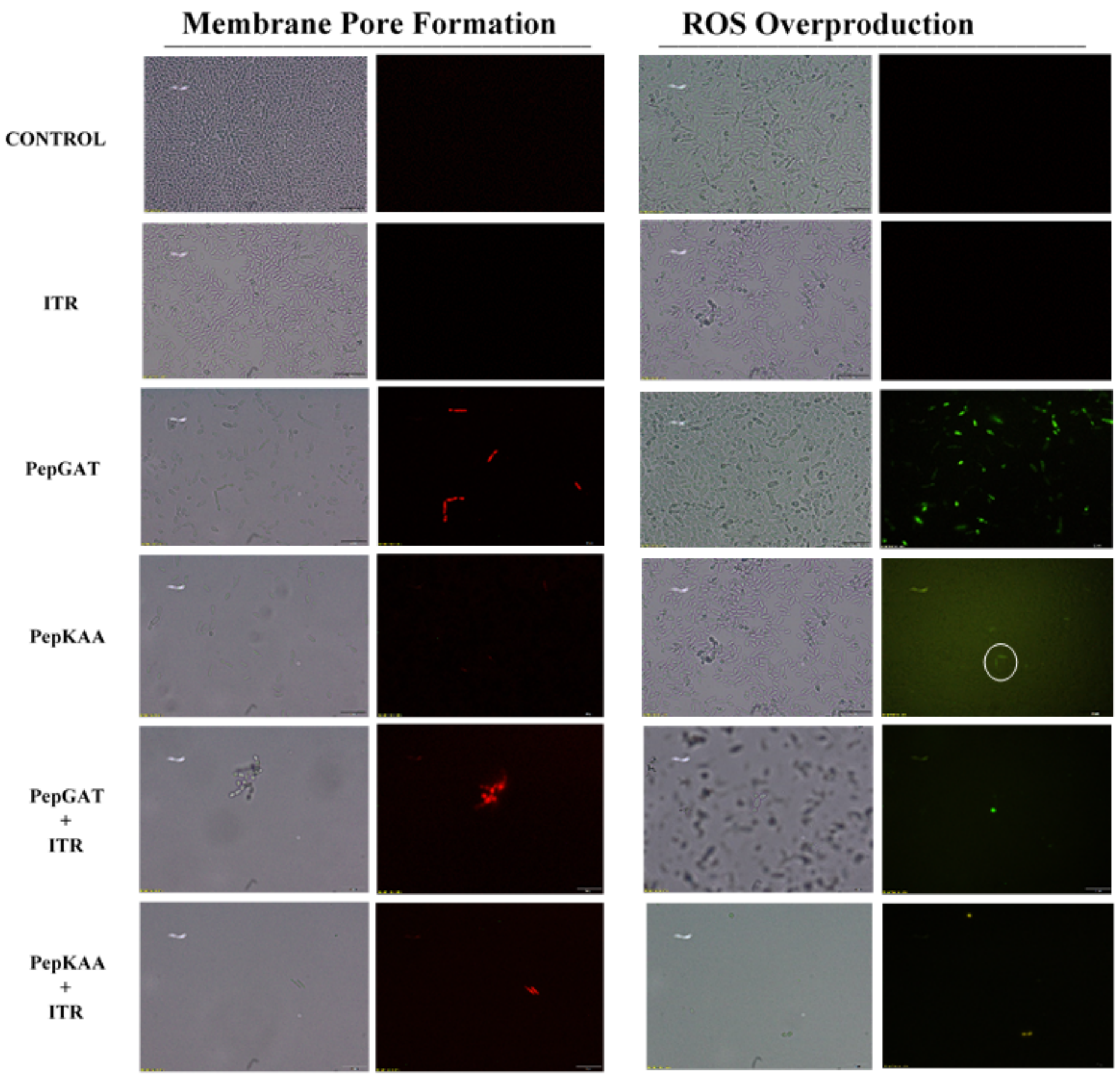

Figure 2

Fluorescence images showing membrane pore formation and ROS overproduction as mechanism of action to inhibit biofilm formation of $\mathrm{C}$. krusei. Control solution of DMSO-NaCl, treated with ITR alone at $1000 \mu \mathrm{g} \mathrm{mL}-1$, PepGAT and PepKAA both alone at $50 \mu \mathrm{g} \mathrm{mL-1}$ and synergistic activity of PepGAT and PepKAA with Itraconazole. Membrane pore formation was measured my propidium iodide uptake assay and ROS overproduction was detected using 2', 7' dichlorofluorescein diacetate (DCFH-DA). 


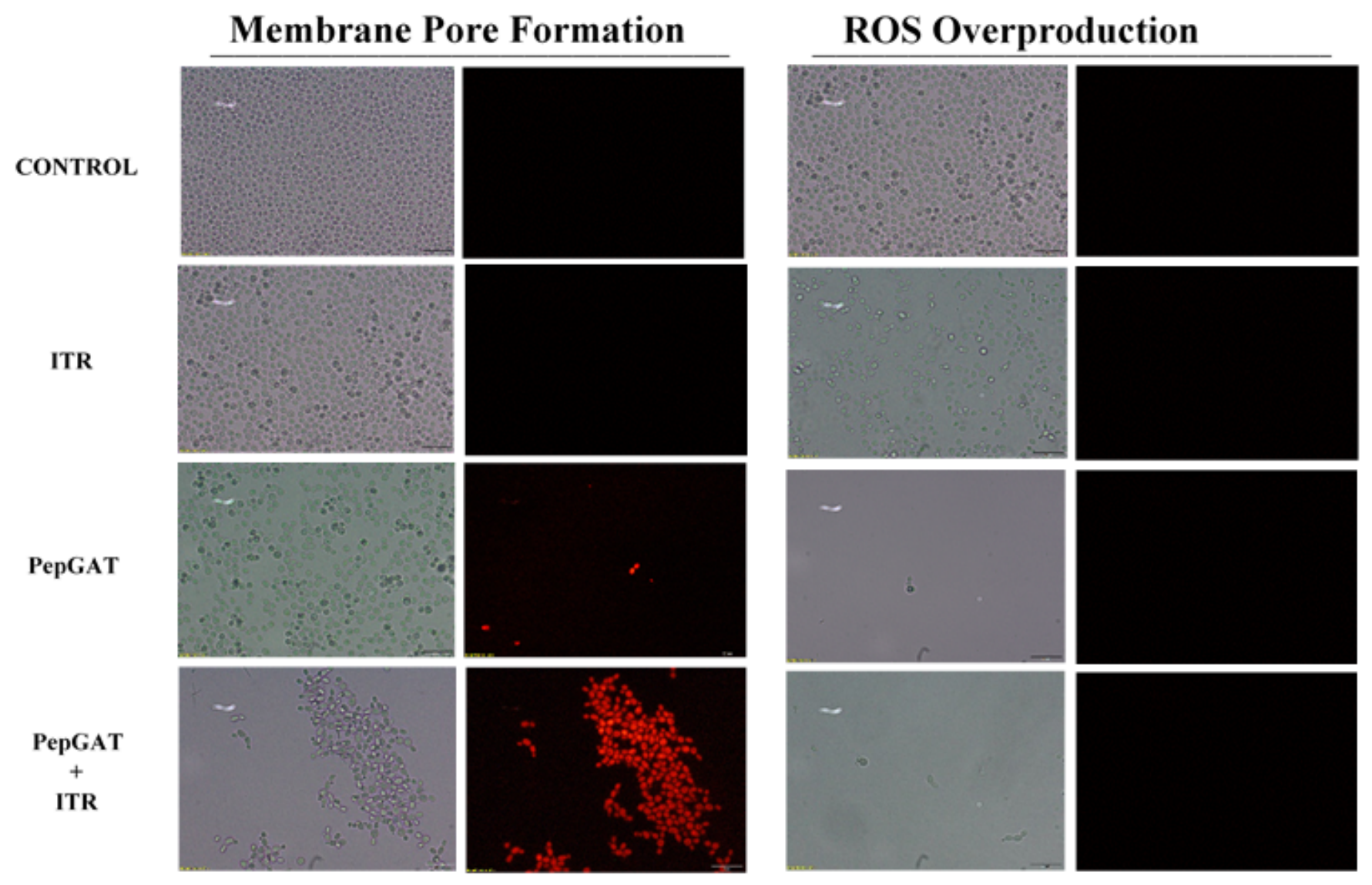

\section{Figure 3}

Fluorescence images showing membrane pore formation and ROS overproduction as mechanisms of action to inhibit biofilm formation of C. albicans. Control solution of DMSO-NaCl, treated with ITR alone at $1000 \mu \mathrm{g} \mathrm{mL-1,} \mathrm{PepGAT} \mathrm{and} \mathrm{PepKAA} \mathrm{both} \mathrm{alone} \mathrm{at} 50 \mu \mathrm{g} \mathrm{mL-1}$, and synergistic activity of PepGAT and PepKAA with ITR. Membrane pore formation was measured by propidium iodide uptake assay and ROS overproduction was detected using 2', 7' dichlorofluorescein diacetate (DCFH-DA). 


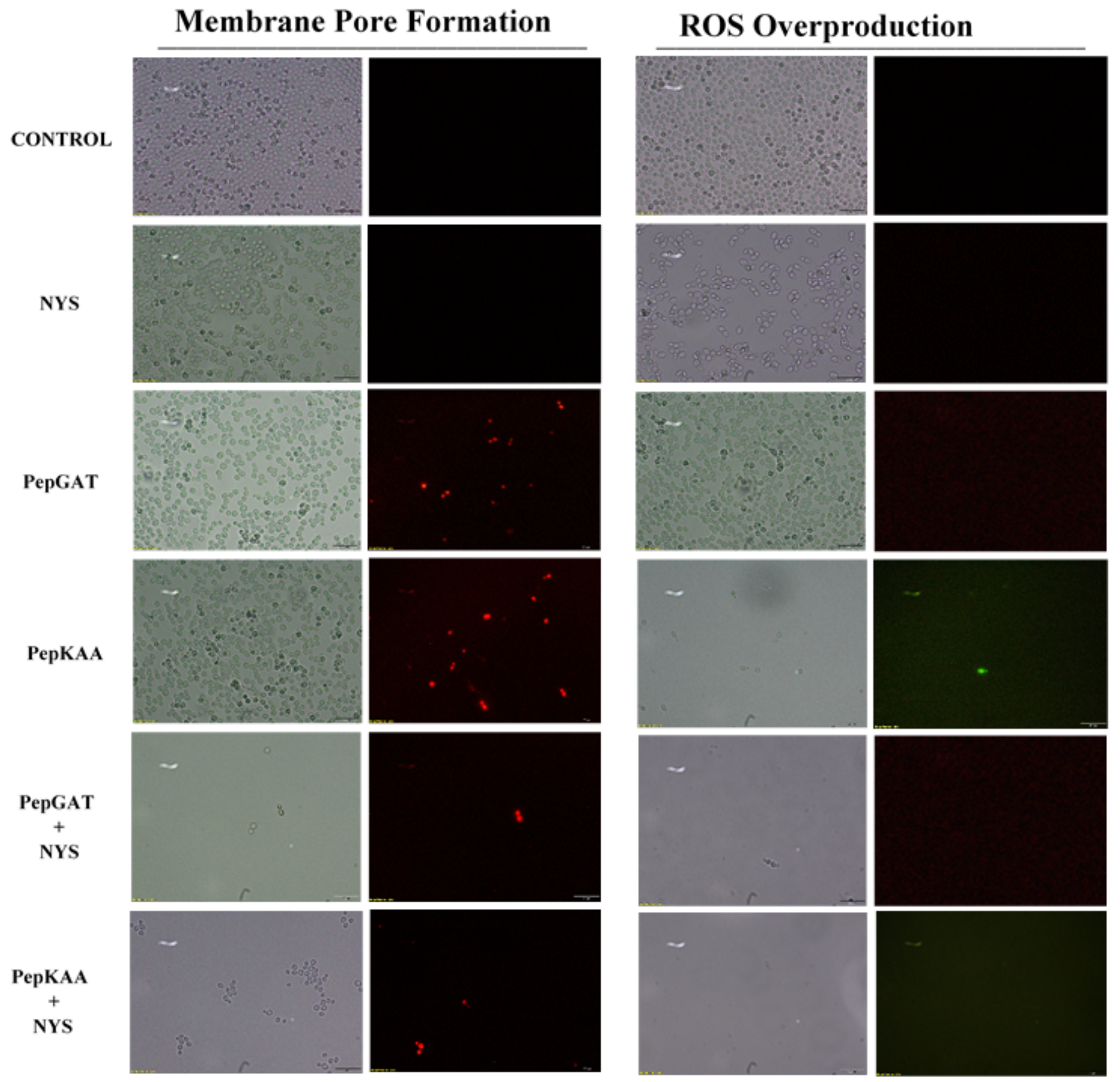

Figure 4

Fluorescence images showing membrane pore formation and ROS overproduction as mechanisms of action to inhibit biofilm formation of $\mathrm{C}$. albicans. Control solution of DMSO-NaCl, treated with NYS alone at $1000 \mu \mathrm{g} \mathrm{mL-1}$, PepGAT and PepKAA both alone at $50 \mu \mathrm{g} \mathrm{mL-1}$, and synergistic activity of PepGAT and PepKAA with NYS. Membrane pore formation was measured by propidium iodide uptake assay and ROS overproduction was detected using 2',7' dichlorofluorescein diacetate (DCFH-DA). 


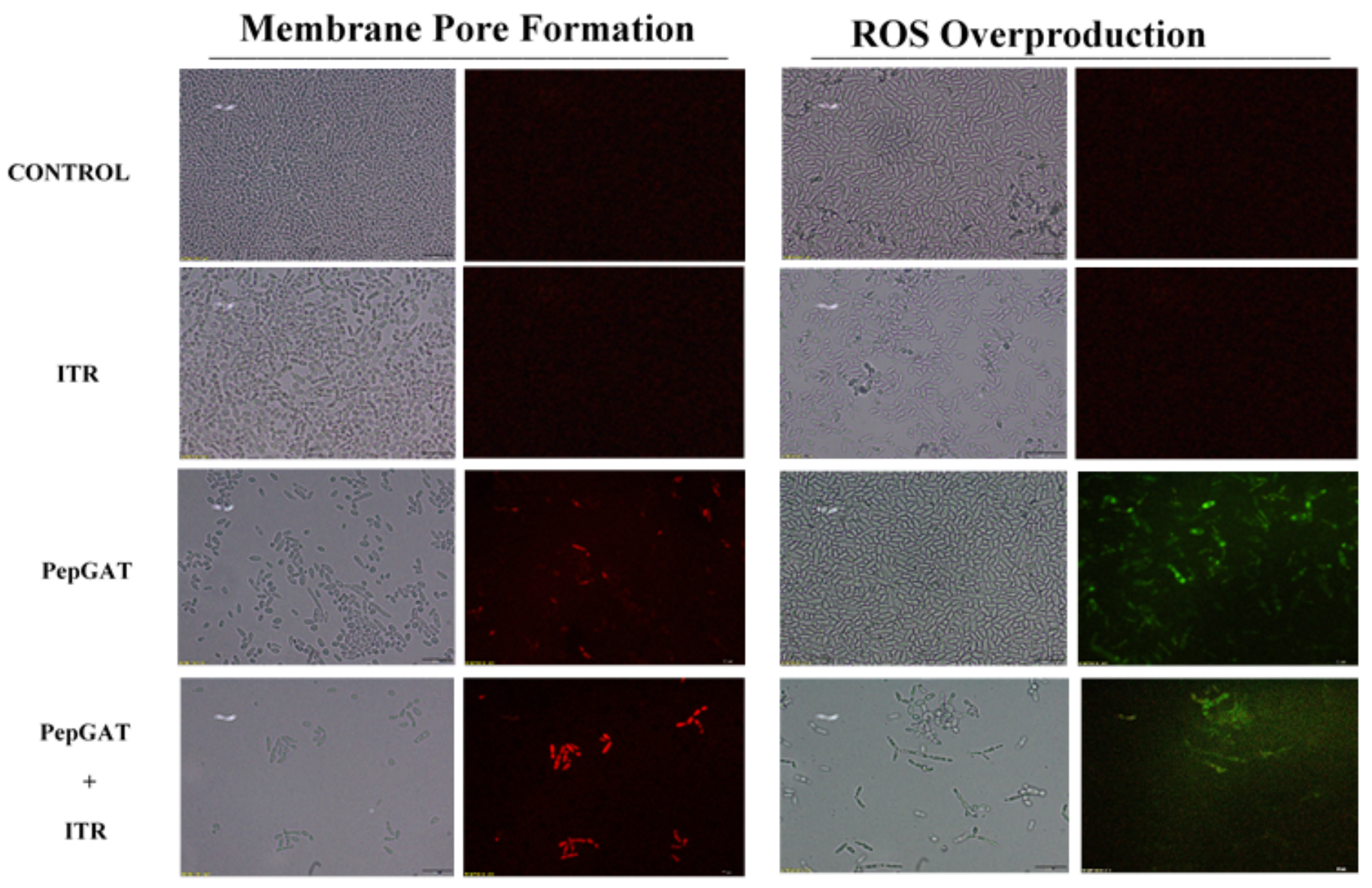

\section{Figure 5}

Fluorescence images showing membrane pore formation and ROS overproduction as mechanisms of action to degrade biofilm formation of $\mathrm{C}$. krusei. Control solution of DMSO-NaCl, treated with ITR alone at $1000 \mu \mathrm{g} \mathrm{mL-1,} \mathrm{PepGAT} \mathrm{and} \mathrm{PepKAA} \mathrm{both} \mathrm{alone} \mathrm{at} 50 \mu \mathrm{g} \mathrm{mL-1,} \mathrm{and} \mathrm{synergistic} \mathrm{activity} \mathrm{of} \mathrm{PepGAT} \mathrm{and}$ PepKAA with ITR. Membrane pore formation was measured by propidium iodide uptake assay and ROS overproduction was detected using 2',7' dichlorofluorescein diacetate (DCFH-DA). 

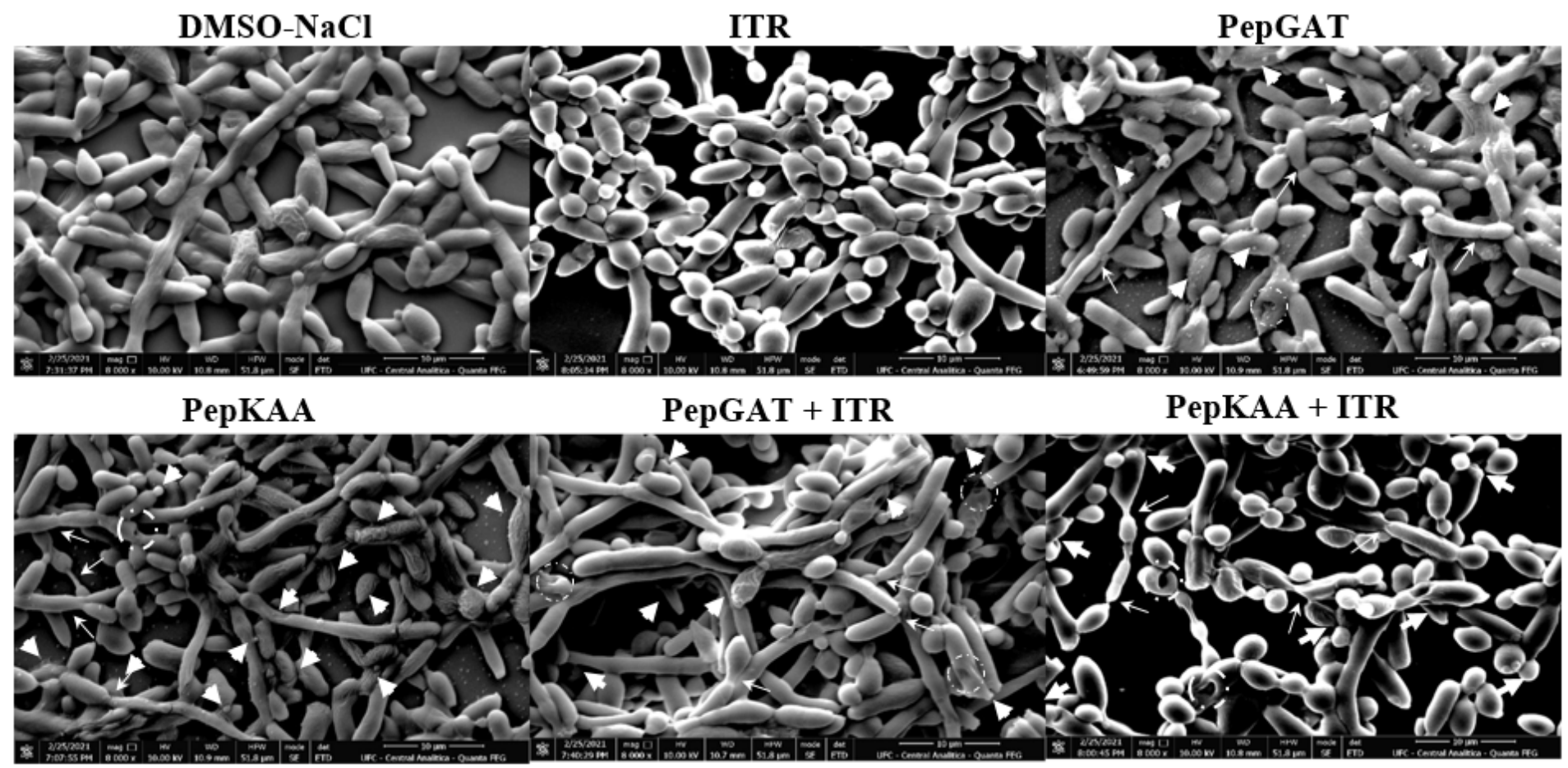

Figure 6

SEM images showing alterations in the biofilm of C. krusei cells after incubation with synthetic peptides, antifungal drugs, and combination by them. The surface of biofilm control (DMSO-NaCl panel) cells is covered by well-defined and organized structures. Biofilm cells exposed to ITR, showing few alterations in the cell surface. PepGAT and PepKAA-treated cells, showing some alterations in cell structure, such as scars, buds scars, and distortion in the shape of the cells. Biofilm cells were incubated with PepGAT and PepKAA in contact with Itraconazole, resulting in strong alterations in the cell membrane, scars, bud scars, and deformation of the cells. 

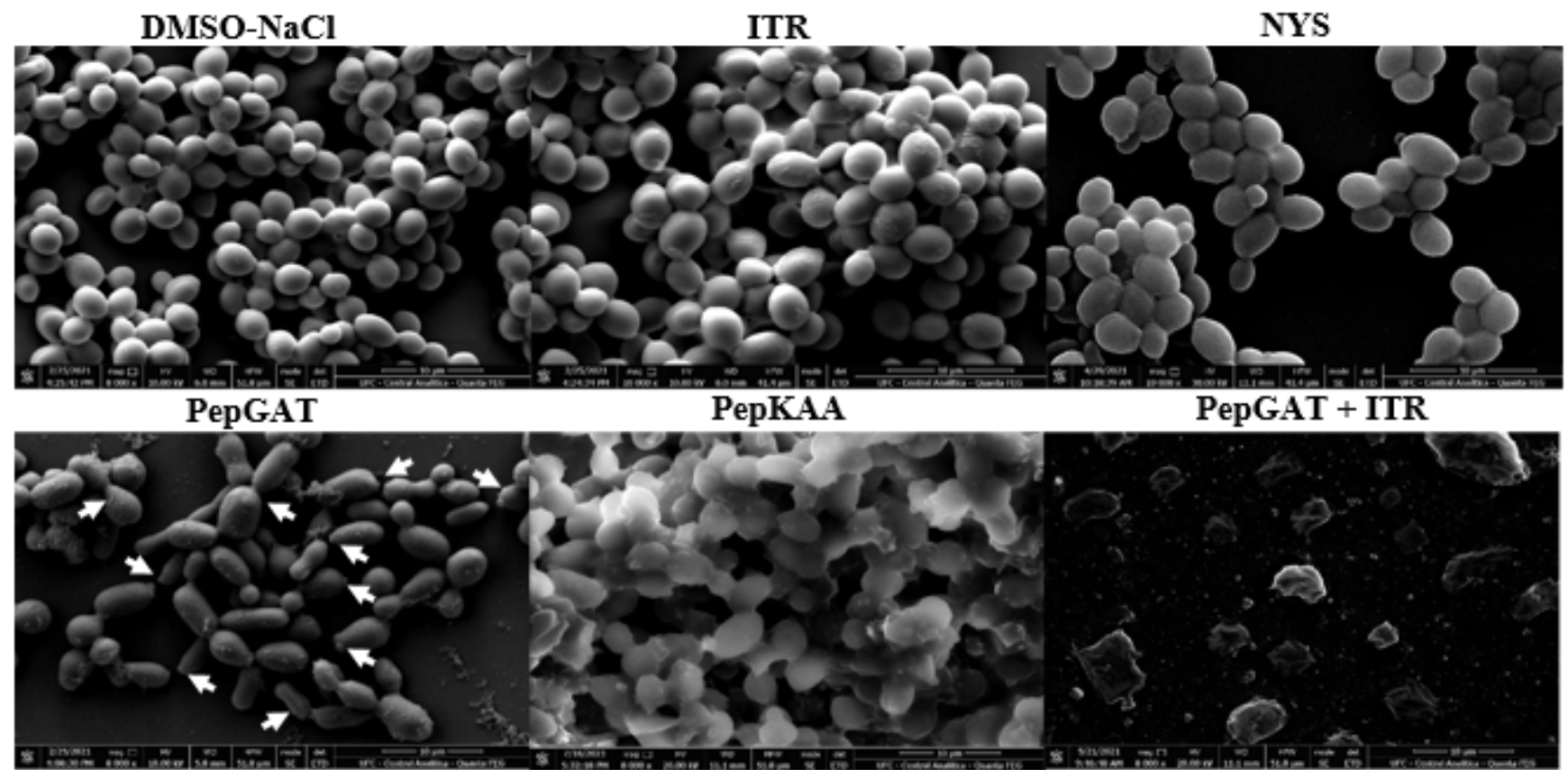

PepKAA

PepGAT + ITR

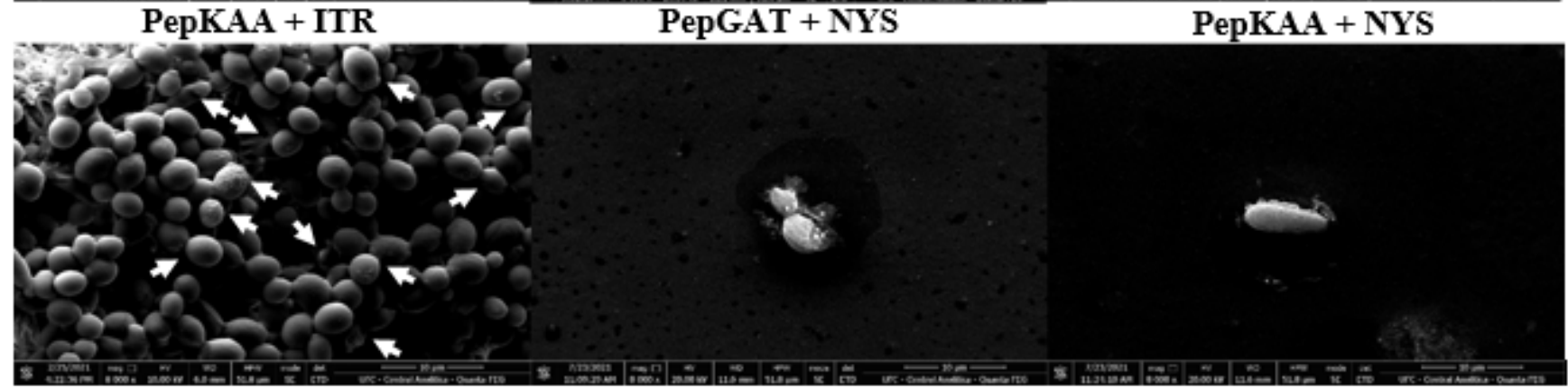

Figure 7

SEM images showing alterations in the biofilm of C. albicans cells after incubation with synthetic peptides, antifungal drugs, and combination by them. The surface of biofilm control (DMSO-NaCl panel) cells is covered by well-defined structures. No relevant changes were seen in the biofilm exposed to ITR and NYS. PepGAT and PepKAA-treated biofilm, showing alterations in the cell membrane, scars, bud scars, and distortion in the biofilm structure. Biofilm exposed to combinations made by PepGAT and PepKAA in a synergistic action with ITR, showing strong alterations in the shape of cells, and buds scars. Biofilm incubated with PepGAT and PepKAA in contact with NYS, what is seen is no biofilm anymore, are only the remaining dead cells. 


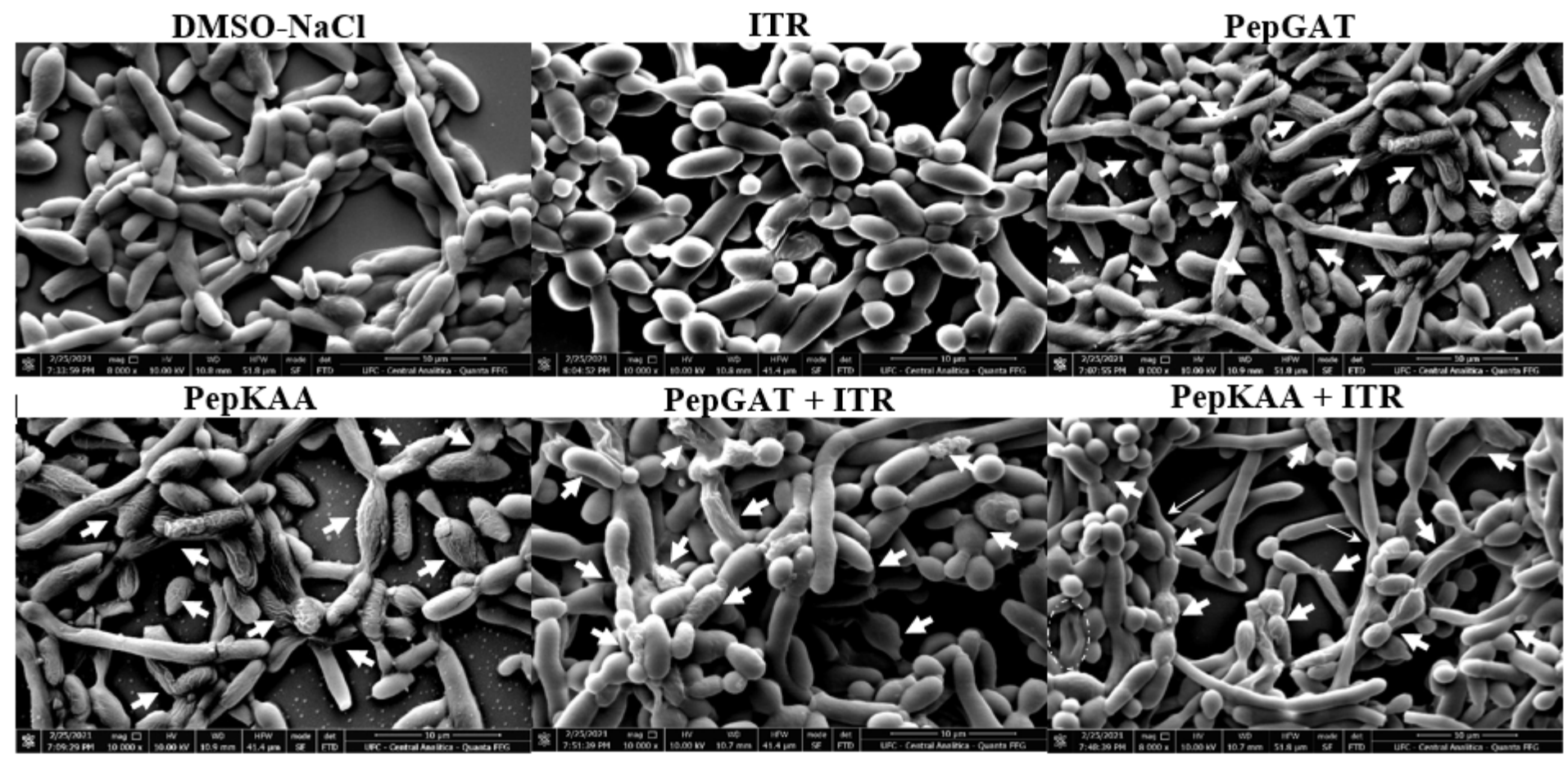

Figure 8

SEM images showing alterations in the preformed biofilm of $\mathrm{C}$. krusei cells after incubation with synthetic peptides, antifungal drugs, and combination by them. The surface of biofilm control (DMSO-NaCl solution) is well-defined and organized. Biofilm exposed to ITR, showing few alterations in the cell surface. PepGAT and PepKAA-treated biofilm, showing alterations in cell structure, such as scars, bud scars, and distortion in the shape of the cells. Biofilm incubated with a combination of PepGAT or PepKAA and ITR, resulting in strong alterations in the cell membrane, scars, bud scars, deformation of the cells structures, and leakage of internal content. 


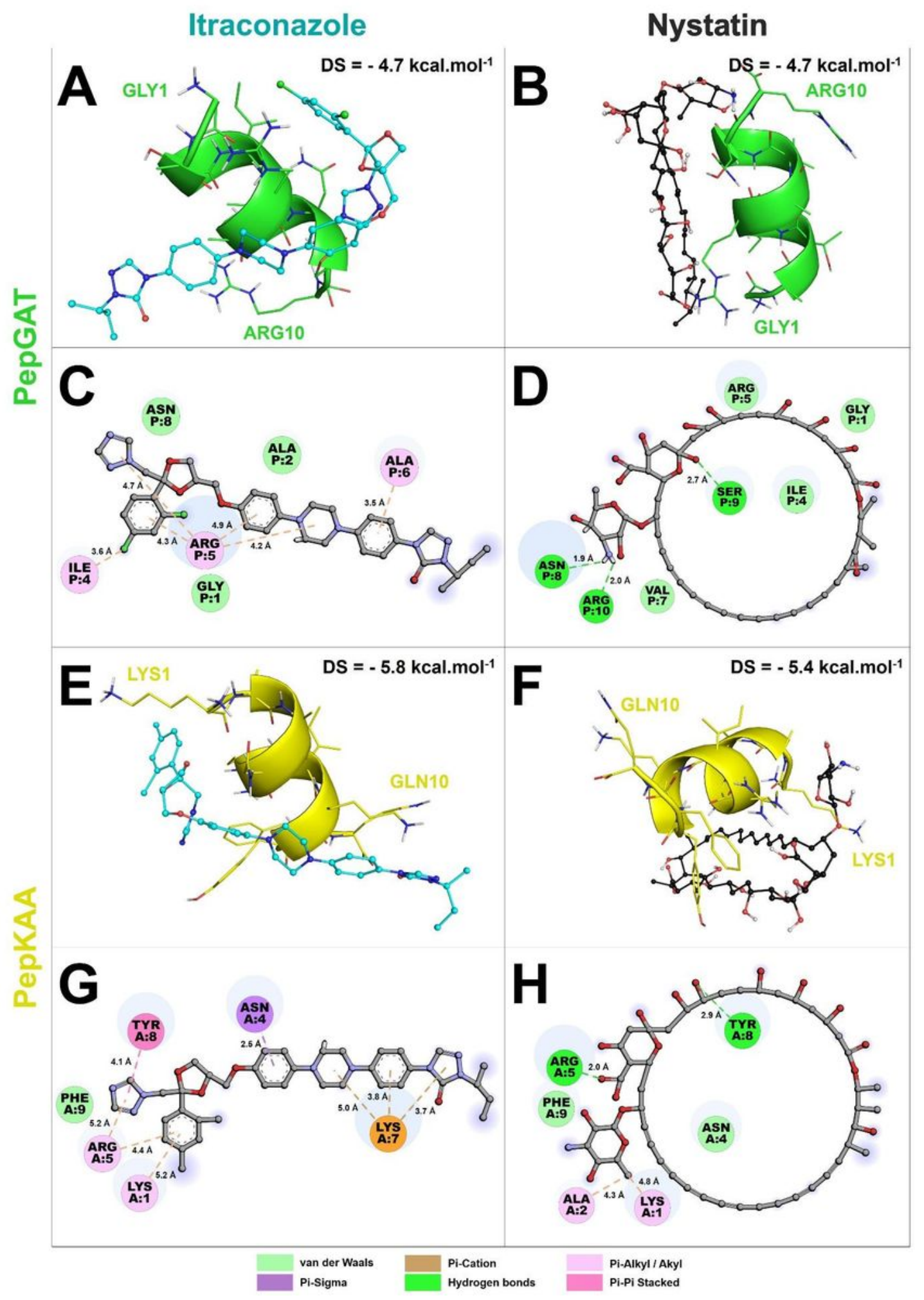

Figure 9

2D and 3D interaction representation between antimicrobial peptides PepGAT and PepKAA with antifungal drugs Nystatin and Itraconazole. (A) 3D interaction representation between PepGAT and Itraconazole. (B) 3D interaction representation between PepGAT and Nystatin. (C) 2D interaction representation between PepGAT and Itraconazole. (D) 2D interaction representation between PepGAT and Nystatin. (E) 3D interaction representation between PepKAA and Itraconazole. (F) 3D interaction 
representation between PepKAA and Nystatin. (G) 2D interaction representation between PepKAA and Itraconazole. $(\mathrm{H})$ 2D interaction representation between PepKAA and Nystatin. The peptides PepGAT and PepKAA are represented in green and yellow, respectively, and the drugs itraconazole and nystatin are represented in cyan and black, respectively. Hydrogen bonds, Pi-Sigma, Pi-Cation, van der Walls, Pi-alkyl, and Pi-Pi Stacked interactions are represented by green, purple, brown, cyan, pink, and dark pink dashed lines, respectively. DS is an abbreviation for Docking Score. 